\title{
Hell or High Water? An Economic Analysis of the Swedish Institutions for Flood Risk Management
}

\author{
Erik Lenntorp \\ Department of Management and Engineering, Linköping University, 58183 Linköping, Sweden. \\ E-mail: erik.lenntorp@liu.se
}

Regulation of waters to generate electricity contributes to two different, but related flood risks. A dam may break resulting in a catastrophic accident. "High flow" floods are less costly and occur when there are large amounts of rain falls in combination with filled reservoirs. Here, the Swedish approach to flood risk management is studied from a social welfare perspective. Risk of dam owner insolvency implies that strict liability should be combined with regulation to prevent dam breaks. Negligence is argued to be the appropriate liability rule for high flow floods. Negligence assures that dam owners do not avoid liability by raising water levels in their reservoirs, and thereby increasing the risk of dam breaks. High flow floods are inevitable. The best strategy is to reduce the ensuing costs by appropriately incorporating flood risks in land use regulation, and by pricing flood risk in available property insurance.

The Geneva Papers (2008) 33, 323-336. doi:10.1057/gpp.2008.5

Keywords: hydropower generation; flood risk; licensing; strict liability; negligence; insurance

\section{Introduction}

This paper investigates the social welfare implications of the institutions managing flood risks associated with hydropower generation in Sweden. A hydroelectric dam contributes to two different, but related flood risks. A dam may break. Such an accident is a potential catastrophe with large losses to property, and possibly to lives. The causes of a dam break are largely within the control of the dam owner: the design of the dam, the amount of water stored in the reservoir and safety efforts. However, floods may also occur when a dam does not break. The prime cause of such a flood event is natural as when there are large amounts of precipitation - a situation called "high flows". Even though the dam owner cannot affect the precipitation, the dam owner significantly contributes to the risk of a flood by the amount of water stored in the reservoir. The consequences of a high flow flood event are considerably smaller than those of a dam failure and involve lesser (although still considerable) damages to downstream property.

The Swedish institutions for flood risk management currently consist of a combination of regulation, liability rules, land-use regulations, and insurance. To construct and operate a hydroelectric dam the owner needs to hold a license. Safety regulations are then attached as license conditions. The main purpose of the safety regulations is to avoid a dam break. However, if a dam breaks, then the dam owner is strictly liable for the ensuing damages. On the other hand, if a flood occurs due to high 
flows and the dam does not fail, then the dam owner is only liable for the damages if he has been negligent. Moreover, a strong regulatory compliance defense is granted; a dam owner in compliance with his license will not be found negligent.

During the 1990s, and also in the year 2000, Sweden experienced repeated high flow flood events in regulated waters. Damages for the year 2000 flood are estimated to be SEK 1.5 billion. ${ }^{1}$ The hydropower producers were in all cases in compliance with their licenses, and the downstream property owners received no compensation from them. This sparked a debate over the responsibility of the hydropower producers for high flow floods. Mantaye ${ }^{2}$ argued that the liability rule should be changed from negligence to strict liability, the main argument being that strict liability would cause hydropower producers to internalize flood damages when they decide on how much water to store in the reservoirs.

The aim of this paper is to study the efficiency of the institutions aimed at managing flood risks associated with hydropower development. Special attention is directed towards the question of whether strict liability is preferable to negligence. The main difference from Mantaye is the focus on the interdependency of the risk of dam break and measures to avoid high flow floods. The analysis here finds support for maintaining the current negligence regime. Moreover, the main recommendation is that damages from high flow floods are best managed by increasing the incentives for downstream property owners to take flood risk into account when developing their properties. This should be done by a better awareness of flood risk in physical planning, when granting building licenses to downstream property owners, and by a better pricing of this risk in the property insurance.

The paper is organized as follows: The next section describes hydropower production and its contribution to flood risks, the following section gives an overview of relevant legislation, in the next section an economic analysis is performed, the penultimate section discusses why flood damages are so large, and finally, the last section offers some concluding remarks, including a brief outlook of possible impacts of climate change.

\section{Hydroelectric power production and flood events}

Regulation of water flow to generate electricity mainly aims at redistributing the natural flow variation to be better aligned with the seasonal variation in electricity demand. The power producer wants to produce the most electricity during the winter months when demand in Sweden is high. Consequently, water is stored in the reservoirs during the spring and the summer to be used for electricity production during the winter. To be able to store water in a reservoir a dam is often constructed. In Sweden there are about 10,000 dams; of these 190 are higher than $15 \mathrm{~m}$. To produce electricity the water is led through the hydropower plant. Water that is not used for electricity production is released through spillways.

\footnotetext{
${ }^{1}$ Mantaye (2002).

${ }^{2}$ Ibid.
} 


\section{Flood events, injurers and victims}

Hydroelectric dams may contribute to two different types of flood events. A dam may break. Such an accident is likely to result in losses to life and property on a catastrophic magnitude. The causes of a dam break are largely within the control of the dam owner: the design of the dam, maintenance, amount of water stored in the dam, and various other safety efforts. That the dam owner can be seen as an "injurer" in the case of a dam break is straightforward.

The other flood event is caused by high flows, that is, a rise above the normal water level. High flows are naturally occurring due to above normal amounts of precipitation. In unregulated waters high flows usually occur in the spring when the snow melts. In regulated waters the spring flood is typically stored in the reservoirs. Hydropower production thus reduces the risk of spring floods. But hydropower development increases the risk of autumn floods when reservoirs are filled in the late summer. However, it could be noted that the rise of the water level in an autumn flood in regulated water is typically not above the corresponding unregulated level although the concern here is that the level is above the normal. The dam owner may be regarded as the "injurer" at least for autumn floods, since the decisions of a dam owner, that is, the filling of the dam, has a significant impact on the flood. For example, by reducing the amount of water that is stored in a dam, a flood may be avoided or at least reduced. The large floods in regulated waters in 1993, 1998 and 2000 were all autumn floods. The consequences of a "high flow"-flood event are considerably smaller than those of a dam break and typically involve only property damages.

However, a flood event is clearly a bilateral accident; if no one lives in the area which may be flooded, then the amount of damages is significantly reduced. In the case of a dam break, a large area will be flooded. To avoid settlements altogether in this area would be very costly. Furthermore, the probability of a dam break is also very small. Consequently, the risk may be difficult to foresee for potential victims. However, the area flooded in a high flow situation is more limited and easier to foresee. High flows occur repeatedly, although more unpredictably in regulated than in unregulated waters. It seems reasonable to emphasize the bilateral nature of flooding in the case of high flows rather than of a dam break.

\section{Overview of the legislation}

\section{Licensing}

To construct and operate a hydropower plant, including the dam and the reservoir, the owner is required by the Swedish Environmental Code ${ }^{3}$ to hold a license (Chapter 11, Section 9). The license is typically granted by an Environmental Court. The license should only be granted if the social benefits are larger than the social costs (Chapter 11, Section 6). The benefits are mainly the value of the electricity produced, while the cost includes environmental impairment and flood risks. The Environmental court

\footnotetext{
${ }^{3}$ SFS (1998).
} 
assesses the appropriateness of the suggested location of the facility. Normally, the Environmental court attaches environmental and safety standards as conditions of the license. Often, the license contains an upper and a lower limit of the amount of water stored in the reservoir. The lower limit is mainly for environmental purposes. ${ }^{4}$ The upper limit is a safety standard set to ensure that the dam will not break. Measures to avoid dam break are subject to considerations based on both the Best Available Techniques-criterion in Chapter 2 (Section 3), and, possibly, the social cost-benefit test in the Environmental Code. There are very seldom any restrictions on the maximum amount of water discharged from the reservoir. At least an amount equal to the inflow is allowed to be released downstream. License conditions also prescribe certain safety measures not concerned with the handling of the water. However, it should be noted that the license conditions do not encompass all measures concerning dam safety. Industrial self-regulation to further dam safety is relied upon to a large degree.

A license is valid indefinitely. However, after 10 years the license and the conditions therein may be reviewed. ${ }^{5}$ It is unclear whether new conditions must also satisfy the social cost-benefit rule. However, the new conditions are not allowed to seriously impair the current activity. In any case, the licensee is entitled to compensation for losses larger than 5 per cent or 20 per cent of the total production value. ${ }^{6}$

The county council is entitled to monitor compliance with the license and report violations. Both administrative and criminal sanctions may be levied.

\section{Liability}

If a dam breaks the dam owner is strictly liable for the damages incurred (Chapter 11, Section 18). If a flood event occurs, but the dam does not break, for example, due to "high flows", the dam owner is only liable if he has been negligent. However, if the dam owner has complied with the license conditions, he is typically not found negligent. Consequently, a strong compliance defense is granted. On the other hand, if a flood occurs and the dam owner has not acted in accordance with the license conditions negligence is almost certain.

All licensed activities are also subject to a compulsory liability insurance scheme (Chapter 33, Section 1). The aim is to provide compensation when this cannot be received from the liable party.

\footnotetext{
${ }^{4}$ Other typical conditions are regulation of the minimum amount of water released from the reservoir, or prescribing a minimum downstream water level. These conditions are also mainly for environmental or recreational purposes.

${ }^{5}$ Chapter 24, Section 5. For some older hydropower licenses issued under previous legislation review is only possible after 30 years.

${ }^{6}$ If the licensee should tolerate losses of 5 per cent or up to 20 per cent depends on the circumstances. In practice, according to Naturvårdsverket (2007) authorities limit new licence conditions in order not to invoke compensation.
} 


\section{Physical planning and building licenses}

Property owners are not allowed to build wherever they want. The type and location of settlements are regulated by the municipalities' development plans, and moreover building licenses must be obtained from the municipality. Building licenses and plans should take into account flood risk (Planning and Building Act, Chapter 2, Section 3). ${ }^{7}$ Moreover, Chapter 7 of the Environmental Code also contains limitations for recreational and environmental purposes on settlements closer than $100 \mathrm{~m}$ from a beach, and in some cases $300 \mathrm{~m}^{8}$

\section{Analysis}

A dam break is likely to have catastrophic consequences. It is reasonable that dam safety be given first priority by the authorities. Consequently, first the risk of a dam break and the appropriate institutions to control this risk are studied. These results will then provide the institutional frame for the subsequent analysis of the flood risk due to a high flow situation.

\section{Dam break}

To simplify, assume that the probability for a dam break only depends on the amount of water stored in the reservoir. Assume that the value of water stored in the reservoir is $\pi(w)$ for the dam owner, and that $\pi(w)$ is increasing in $w$. The probability of a dam break is $q(w)$, where $q$ is an increasing function of $w$. The damage if a dam break occurs is $D$. Social welfare is the sum of the dam owner's profit, and the expected cost of a dam break, that is, $W=\pi(w)-q(w) D$. To find the socially efficient level of water the latter expression is maximized with respect to $w$. The (rearranged) first order condition is $\pi_{w}=q_{w} D$, where subscripts denote first derivatives. ${ }^{9}$ Consequently, the optimal amount of water stored in the dam is when the marginal benefit of storing water $\left(\pi_{w}\right)$ is equal to the marginal cost of water storage, that is, the marginal expected cost of dam failure $\left(q_{w} D\right)$. Let $w_{0}$ denote the efficient level of water stored in the reservoir.

If the dam owner is strictly liable for the damages caused by a dam break, then he will fully internalize the costs of dam failure. This means that the dam owner is induced to store the efficient amount of water $w_{0}$ in the reservoir. However, the resulting damages are likely to be very large. Consequently, there is a substantial risk that the dam owner will be insolvent before all victims are compensated. The bankruptcy problem implies that strict liability results in both under-protection and under-compensation. A general result in the literature is that dilution of liability due to bankruptcy is a reason for primarily relying on regulation to create efficient

\footnotetext{
${ }^{7}$ SFS (1987).

${ }^{8}$ However, out of the 3.5 million houses in Sweden, 426,000 are located closer than $100 \mathrm{~m}$ from a shoreline, see Mannheimer and Svensson (2004).

${ }^{9}$ This notation is used throughout the paper.
} 
incentives. ${ }^{10}$ However, regulation implies that a costly effort on monitoring compliance must be exerted. Another drawback is that regulation does not provide compensation to the victims. The primary focus here is the efficiency of the incentives provided, and not compensation to victims. Moreover, compensation may be achieved through other means. Another possible solution is liability insurance. With liability insurance the insurer determines the appropriate amount of water stored and monitors that the dam owner abides by this level. Consequently, an insurance solution does not relieve society of the moral hazard problem. To ensure that the dam owners do insure, insurance can be made compulsory. ${ }^{11}$

In the Swedish case studied here the amount of water stored in the reservoir is regulated in the license. Considering the bankruptcy problem, it makes sense to use licensing (i.e. regulation) to limit the amount of water stored in the reservoir. The upper limit is set to avoid a dam break. ${ }^{12}$ If the license is enforced, then this provides an efficient control of the risk. The dam owner is also subject to strict liability. Liability for a dam break is imposed regardless of compliance status with the license. Generally, combining regulation and liability is socially preferable. One reason is that the deterrent effect of expected liability adds to the deterrent effect of the expected punishment for violating the license. Thus enforcement expenditure can be saved. Furthermore, by not granting a compliance defense the dam owner is given incentives to take more stringent precautions than those required by regulation (if the precautions reduce the expected liability by more than they cost). ${ }^{13}$ Additionally, strict liability provides incentives for the dam owner to take measures not covered by regulation to reduce the risk. Taken together, the combination of licensing and strict liability looks to at least approximately give optimal incentives to control the risk of dam break.

A question is whether insurance could be substituted for the license to overcome the bankruptcy problem. Swedish dam owners have a collective insurance for dam break liabilities. Furthermore, the Environmental Code contains a compulsory insurance scheme for dam owners. However, insurance does not seem to be likely to perform the role of the license. One reason is that the insurance premiums are not appropriately differentiated for the risk imposed by an individual dam. In particular, the compulsory liability insurance of the Environmental Code contains no risk differentiation. ${ }^{14}$ This implies that the appropriate incentives for precautions like the siting of dams and safety measures are not created. Support for this claim can also be found by the recent harsh critique levied by the Swedish National Audit Office concerning the effectiveness of the hydropower producers dam safety self-regulation. ${ }^{15}$ Another reason to maintain

${ }^{10}$ e.g. Shavell (1984).

${ }^{11}$ See Faure (2006).

${ }^{12}$ As mentioned, measures to avoid dam break are based on both the Best Available Techniques-criterion, and, possibly, the social cost-benefit test in the Environmental Code. As a rough approximation, we may regard the limit to be the determined basis on a social welfare calculus, and thus to be efficient.

${ }^{13}$ The costly process of license review and possible compensation to the hydropower producer for lost production value can then be avoided. Under strict liability, the dam owner may have incentives to overcomply with the license and voluntarily reduce the water level in the reservoir to avoid a dam break.

${ }^{14}$ SOU (2007).

${ }^{15}$ Riksrevisionsverket (2007). 
reliance upon licenses may be that the licensing authority may be better at determining the efficient amount of water stored compared to an insurer. Typically, regulated waters include many dam constructions with separate owners, which to some extent must be synchronized. Determining the optimal regulation of waters also entails considering the consequences for the environment, recreation, and transportation. Regulatory agencies may also have a comparative advantage over insurers in overcoming the moral hazard problem. Furthermore, Faure notes that insurance companies seem reluctant to take over enforcement responsibilities from regulatory agencies. ${ }^{16}$ For the remainder of the paper the analysis focuses on the role of licensing and liability to control the dam owner.

\section{High flow situations}

We start from a situation where the upper limit of how much water can be stored in the reservoir is determined in the license. The dam owner is strictly liable in case of a dam break. Now we shall proceed to the issue of how to control the flood risk caused by high flows, that is, a larger amount of precipitation than normal. Recall that the dam owner wants to redistribute electricity production to the winter months. To do this he must fill the reservoir by late summer/early fall. If a large amount of rain falls when the reservoir is filled, then we are in a high flow situation. If the dam owner simply releases the additional water through the spillways, then a flood occurs.

Assume that we have a dam of a certain height, capacity of the power plant, and spillways. ${ }^{17}$ The dam owner holds a license. The license contains an upper limit on the amount of water to be stored in the reservoir equal to $w_{0}$. The limit is socially efficient to avoid a dam break. However, it is possible to store more than this amount. The capacity of the power plant is limited to $w_{0}$ in each production period. There is no restriction on the capacity of the spillways, that is, any amount of water can be released. The profit is as before $\pi(w)$, which is increasing in $w$. Moreover, if $w_{0}$ is released the downstream water level is normal and no flood occurs. If an amount in excess of $w_{0}$ is released through the spillways a flood occurs.

The model contains four time periods. This is to mimic the annual cycle of hydropower production. In the first period the dam owner receives an endowment of water of $w_{0}$. He has the choice to store the entire amount, or part of this amount. In this period no production takes place, so a release of water does not yield any profit. In the second period the dam owner gets an additional, but uncertain, endowment. With probability $(1-p)$ he receives an inflow of $w_{0}$, and with probability $p$ he gets $w^{+}>w_{0}$. He must now decide on how much to release, and how much to store in the second period. In the third period, only production takes place. Finally, in the fourth period the dam owner may release any water left in the reservoir, but without being able to sell any of the electricity produced in this period.

\footnotetext{
${ }^{16}$ Faure (2006).

${ }^{17}$ This assumption is reasonable, since expansion of Swedish hydropower production through new dams is negligible.
} 
Consequently, the (annual) profit of the dam owner is the combined profits from the water released in the second and third periods. There is no discounting, which seems reasonable considering that the second and third periods are supposed to span only the winter months when electricity demand is high.

Let us first consider the dam owner's decision to store $w_{0}$ in the first period. If the second period endowment is the normal amount, $w_{0}$, then there is no problem. An input of $w_{0}$ water is available in both the second and the third periods. Production earns a profit of $\pi\left(w_{0}\right)$ in each period, and no flooding results. However, if the second period brings the larger endowment $w^{+}$, then we are in a high flow situation. If the dam owner releases the entire endowment $w^{+}$, then he will cause a flood downstream. Damage from such a flood is assumed to be $d>0$. Production is limited to $w_{0}$. In the third period he empties the reservoir and releases the remaining amount of water $w_{0}$. Alternatively, the dam owner can prevent the flood by only releasing $w_{0}$ in the second period. This implies that he instead stores $w^{+}$. In the third period he releases $w_{0}$ and receives a profit of $\pi\left(w_{0}\right)$, and in the fourth period he empties the reservoir by releasing $w^{+}-w^{0}$. The last release will not generate any profit, but will not cause any flood either. However, the increased storage of water in the second period increases the probability of a dam break, defined by $q_{w} \cdot\left(w^{+}-w^{0}\right) D$, where $q_{w}$ is the first derivate of the probability function for a dam break.

However, by storing $w^{\text {safe }}=w_{0}-\left(w^{+}-w_{0}\right)$ in the first period the dam owner can avoid high flow floods. ${ }^{18}$ In such case, if the second period endowment is normal, then the dam owner releases $w_{0}$ in that period, and $w^{\text {safe }}$ in the last period. The value of total production is $\pi\left(w_{0}\right)+\pi\left(w^{\text {safe }}\right)$. If the second period endowment is $w^{+}$, then $w_{0}$ is released in both periods. Consequently, total value of production is $\pi\left(w_{0}\right)+\pi\left(w_{0}\right)$. Obviously, the drawback from this strategy is that with normal precipitation some production is lost. The dam owner's possible decisions, and their consequences, are illustrated in Figure 1.

It is also possible to decrease the risk of high flow floods by building additional reservoirs and/or to increase the height of the dams. However, a Swedish government report dismisses both these options as too costly compared to the reduction in high flow flood risk achievable. ${ }^{19}$ Consequently, these options are not further considered in the paper.

The first question to discuss is which strategy is optimal from a societal point of view. Then we will discuss how this strategy can be achieved.

If we are in a high flow situation would we like the dam owner to release the additional amount of water and cause a flood, or store and increase the risk of a dam break? There seems to be a consensus that increasing the risk of dam breaks should be avoided. A Swedish government report claims that storing more water than the upper limit should not be considered as an option to reduce high flow flood risk, since that would endanger dam safety. ${ }^{20}$ The report also states that dam safety must in all situations have first priority, and water should always be released such that dam safety

\footnotetext{
${ }^{18}$ It is assumed that $w^{\text {safe }} \geqslant 0$.

19 SOU (2007).

${ }^{20}$ SOU (2002).
} 


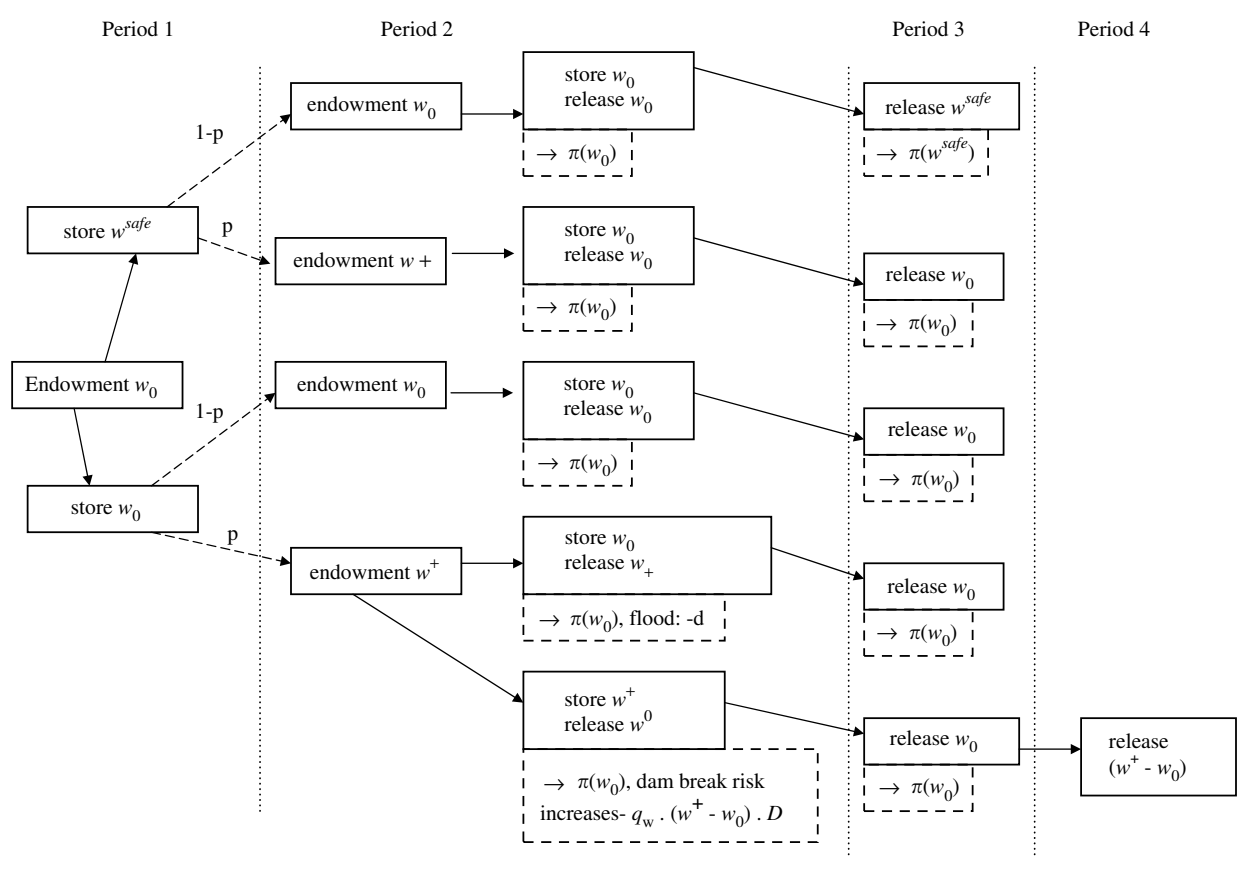

Figure 1. Dam owner's decisions.

is not endangered. For this reason licenses do not include upper limits on the release of water through spillways. ${ }^{21}$ Given this, we assume that from a societal point of view $d<q_{w}\left(w^{+}-w_{0}\right) D$. Consequently, if a dam owner has stored $w_{0}$ in the first period, we want him to cause a flood in a high flow situation.

However, we still have the option to avoid the flood altogether by lowering the amount of water stored in the first period. The question is then whether the lost production is larger than the expected costs of a flood. According to the above cited government report the upper limit should not be lowered to reduce flood risk in a high flow situation. ${ }^{22}$ As in the model, the rationale is the foregone production. In the report a reference is made to a study of a 1-m reduction of the upper limits in five large reservoirs in five different rivers. The study finds that the power producers would lose annual earnings of SEK 500 million. It would also imply that the level of water in the water systems would generally be lowered, which would have adverse effects on aquatic life, recreation, and, paradoxically, on the waterfront property owners (which would no longer have waterfront properties during the summer). Furthermore, the lost electricity would have to be replaced by electricity from other sources; most likely this substitution would result in increased emissions of climate-changing gases. Moreover, the government would have to compensate the power producers for the lost 
production value. Finally, in contrast to the model, this would not be a guarantee against floods; it would only make them less frequent. Consequently, we assume that the expected lost earnings due to the safe option are larger than the expected flood costs, that is, $(1-p) \pi\left(w^{\text {safe }}\right)>p d$. From a social perspective we do no want the dam owner to reduce the water level to avoid high flow floods.

To summarize, we want to induce the dam owner to store $w_{0}$ in the first period, and if a high flow situation occurs, that is, the second period endowment is $w^{+}$, then we want the dam owner to release the additional water through the spillways and thereby cause a flood. Now we turn to the issue of the appropriate instrument to achieve this solution. First, strict liability is discussed and then negligence.

Strict liability: The dam owner will store $w_{0}$ in the first period. The safe option $\left(w^{\text {safe }}\right)$ is clearly inferior, since expected liability from flood damages is less than the lost production. If the dam owner is in a high flow situation, then he will prefer the certain, but smaller, damages $d$ from a flood rather than risk liability for a dam break. Consequently, strict liability for both dam breaks and high flow floods would provide efficient incentives.

As mentioned, in case of a dam break there is a substantial risk of insolvency. If this is the case, we can no longer be certain that the dam owner will prefer the certain damages of $d$ to the increased risk of a dam break. Assume that the limit on liability due to insolvency is $L$. Consequently, if $d>q_{w}\left(w^{+}-w_{0}\right) L$, then the dam owner stores the entire second period endowment $w^{+}$. However, to store the additional amount would imply that the dam owner violates the license and may be subject to sanctions. Enforcing regulation is costly, and enforcement is likely to be less than certain. Typically, combining regulation and liability reduces enforcement costs. In this case the opposite occurs. Note that since the production capacity of the power plant is limited to $w_{0}$ the dam owner receives no extra profit from storing more water than the limit $w_{0}$. The only reason why he may want to violate the license condition is to avoid paying flood damages. Of course, with sufficient enforcement of the license, efficient incentives prevail under strict liability. To conclude, by explicitly considering the interdependency of the risks of a high flow flood and a dam break, the main finding is that imposing strict liability for high flow floods may result in dam owners violating regulations aimed at avoiding a dam break. Strict liability implies that more costly effort has to be spent on enforcing regulations so as not to endanger dam safety. ${ }^{23}$

Negligence: We focus in particular on the combination of a negligence rule with a compliance defense. The compliance defense means that the dam owner is not found negligent if he has complied with the license. Here, this implies that the dam owner can release the additional amount of water, thereby causing a flood, but for whose damages he is not liable. Obviously, the dam owner will not store the additional water. Consequently, the socially optimal strategy is achieved by letting the firm escape liability for the high flow flood event. There is no need to enforce the license condition on the upper limit of water stored in the reservoir, since the dam owner has no

${ }^{23}$ Note that the result holds also if a scheme of compulsory liability insurance is used instead of licensing. The difference is of course that in such case it is the insurer, and not the regulatory agency, which must spend more effort to monitor the dam owner. 
incentives to violate the condition (on the contrary, since he is liable for a dam break he has incentives to avoid a violation). The benefit of using negligence for high flow floods is thus that enforcement does not need to be stepped up to ensure dam safety.

\section{Incentives of the downstream property owners}

As shown above, both strict liability and negligence may give the dam owner efficient incentives. A difference is that with strict liability the downstream property owners are compensated for flood losses, but with negligence (and a compliance defense) the downstream property owners bear the losses. As mentioned, a high flow flood event in particular is to be regarded as a bilateral accident. To be able to discuss the merits of both alternatives, we must first discuss how to present the victims, that is, the downstream property owners, with appropriate incentives.

We begin by considering strict liability. Property owners are fully compensated for high flow flood damage. Consequently, the property owners do not bear any flood risk. This implies that they do not account for the flood risk when deciding how to develop their property. As a result, the property owners may invest too much in areas exposed to flood risk. This problem can be coped with by adding a defense of contributory negligence. ${ }^{24}$ In a bilateral situation, strict liability with a defense of contributory negligence results in efficient incentives for both the injurers and the victims. To avoid the accident cost, victims will in general not be negligent, and, as a consequence, the injurer will be strictly liable.

If the liability rule is instead negligence with a compliance defense, then the downstream property owners bear the losses. In this case the property owners have efficient incentives to take flood risk into account when developing their property. A negative consequence of letting the property owners bear the risk is that they are most likely risk averse. However, downstream property owners can insure against flood risk, and can thus be relieved of the risk. In Sweden, high flow flood risk is covered by the standard property owner's insurance policy. ${ }^{25}$ In this case moral hazard might be a problem, that is, the insured property owner do not sufficiently account for flood risk. Only deductibles are presently used by Swedish insurers to remedy this moral hazard problem. Insurance premiums are not differentiated based on flood risk. Differentiated premiums might be an effective price signal for property owners to account for flood risk.

We can now pose the question whether to use strict liability with a defense of contributory negligence, or negligence (combined with a compliance defense). A general result is that the best rule depends on whether the court can best determine the injurer's or the victim's negligence. ${ }^{26}$ Negligence is preferable if the former is true. If the latter is true, then strict liability is preferable. Arguably, it should be easier to determine the

\footnotetext{
${ }^{24}$ Mantaye (2002) suggests that a rule of strict liability with contributory negligence should be used to deal with high flow flood risk.

${ }^{25}$ However, flooding caused by a dam break is not covered in the insurance policy.

${ }^{26}$ Faure and Skogh (2003).
} 
victim's negligence, that is, is the settlement too close to the water or not? However, the dam owner has an operating license. The license conditions effectively determine the level of due care through the compliance defense. Consequently, the problem of defining the injurer's negligence is not such a difficult task for the court.

However, according to the analysis in this paper there is a reason for preferring negligence. If strict liability with contributory negligence is applied, then property owners will not be negligent. Consequently, the dam owner will be strictly liable. If bankruptcy is a problem, then the dam owner may, to avoid liability, endanger dam safety by storing more than the permitted amount of water. To ensure that this does not happen, more costly efforts must be exerted to enforce the license. This is a cost of strict liability that can be avoided by using negligence. Hence, the argument is that negligence may in fact be the better rule to deal with high flow flood risk.

\section{Why do flood damages occur?}

If the assumption is correct that it is not worthwhile to fill the reservoirs to a lesser degree to avoid high flow floods, then these floods will occur regardless of whether we use strict liability or negligence. A puzzle is why the damages have been so large, given that in Sweden the downstream property owners bear the risk. Put differently, why have the property owners exposed themselves to this risk? Part of the answer is that high flow situations are rare enough that the risk is in general underestimated. In particular, during the 1960s and 1970s flood events were unusually rare. Quite tellingly, it was during the 1960s that most building licenses within $100 \mathrm{~m}$ from water were granted. ${ }^{27}$ The floods of the 1990s were a wake-up call, although these events are actually part of a more normal pattern. Owing to underestimation property owners have most likely not appropriately considered flood risk when developing their property. This problem is further aggravated by the fact that the insurance companies have not differentiated the premiums on the basis of flood risk. A better pricing of flood risk in insurance policies could be a powerful tool to give better incentives to reduce flood damage. The actual possibilities to differentiate premiums should be eased by the fact that flood risk maps have increasingly been developed over the last decade.

Recall that the downstream property owners are also restricted by land use regulation, which supposedly should ensure that houses are not built where flood risk would advise against settlement. Along with the property owners, the municipalities have also neglected flood risk. Investigations by the Swedish National Board of Housing, Building and Planning Legislation show that flood risks have not been appropriately addressed when devising plans and granting building licenses. ${ }^{28}$ However, the floods in the 1990s have put flood risk more firmly on the planning agenda. A recommendation now is to not allow settlements with any significant value within an area likely to be flooded by a 100 -year flow. ${ }^{29}$ Furthermore, flood risk maps have been developed, which should be helpful to prevent flood damage. In a study of

\footnotetext{
${ }^{27}$ Mannheimer and Svensson (2004).

${ }^{28}$ Boverket (2001).

${ }^{29}$ A 100 -year flow is a situation of high flows that are expected to appear every 100 years.
} 
the flood in the year 2000 no properties granted a building license in the last 10 years were damaged. This could partly be attributed to the fact that not much development had occurred in the flooded area during that period and to a successful flood mitigation effort. Without doubt, physical planning plays an important role in limiting the damages from flood risk. However, its efficacy can also be questioned. The incentives for a municipality to disallow development of, for example, attractive waterfront properties may be weak.

Finally, it seems that to reduce the costs of high flow floods the most important actions for social welfare are not to reduce the amount of water stored in the hydropower producers' reservoirs, but to increase the incentives for property owners to develop their property with this risk in mind. Insurance companies can, through differentiated premiums, strengthen the incentives to develop waterfront properties wisely. The municipalities must also play an important role by not allowing settlements likely to be damaged by recurrent high flows. All in all, the case for preserving negligence for the hydropower producers is arguably strengthened by considering the responsibilities of the downstream actors.

\section{Concluding remarks}

In this paper, the social welfare implications of the Swedish institutions for managing flood risk are studied. Special attention is given to the problem of high flow floods, that is, floods occurring due to above normal precipitation in combination with filled reservoirs. Arguments have been put forth to change the liability of hydropower producers from negligence to strict liability for these types of flood events. Considering the interdependent problem of a possible dam break, and the bilateral nature of flood risk, the analysis here finds support for maintaining the current negligence regime. However, this support hinges on some quite specific assumptions of possible insolvency and the social desirability of different courses of actions.

An interesting outlook towards the future is the effect of climate change on the problem studied here. Most likely, climate change increases the frequency of extreme weather conditions. High flows are likely to appear more often. Possibly, this might lead to a lowering of the limits on the permitted water level in reservoirs. However, this will reduce the capacity to generate electricity by the comparatively climate friendly hydropower. This implies an increase in the social costs of lowering the permitted amount of water in the reservoirs. Consequently, climate change may give further grounds for recommending that, given sufficient precautions to avoid dam breaks, flood risk management should not focus on reducing the number of flood events, but instead the costs that these events incur. This should primarily be done by a more active incorporation of flood risk in physical planning, and in the property owners' insurance policies.

\section{Acknowledgements}

Financial support from the Swedish Energy Agency is gratefully acknowledged. I would like to thank two anonymous referees for their useful comments. 


\section{References}

Boverket (2001) Översvämningsfrågor i översiktsplaneringen, Karlskrona: Swedish National Board of Housing, Building and Planning Legislation.

Faure, M. (2006) 'Economic criteria for compulsory insurance', The Geneva Papers on Risk and InsuranceIssues and Practice 31: 149-168.

Faure, M. and Skogh, G. (2003) The Economic Analysis of Environmental Policy and Law, Cheltenham, U.K.: Edward Elgar.

Mannheimer, J. and Svensson, T. (2004) 'Skyddet mot översvämningar måste organiseras batter', Dagens Nyheter (DN Debatt), 15 July.

Mantaye, A. (2002) 'An economic analysis of a Swedish hydropower plant liability case', The Geneva Papers on Risk and Insurance - Issues and Practice 27: 626-637.

Naturvårdsverket (2007) 'Omprövning av vattenverksamhet', Fakta 8287(April): 1-26.

Riksrevisionsverket (2007) 'Säkerheten vid vattenkraftdammar', RiR 9: 1-83.

SFS (1987) Plan och bygglagen (Planning and Building Act), 1987:10, Stockhom: Riksdagstryck.

SFS (1998) Miljöbalken (The Environmental Code), 1998:808, Stockholm: Riksdagstryck.

Shavell, S. (1984) 'Liability for harm versus regulation of safety', Journal of Legal Studies 13: 357-374.

SOU (2002) Miljöbalken under utveckling, ett principbetänkande (Swedish Government Official Reports, 2002:50, Stockholm: Fritzes.

SOU (2007) GMO-skador i naturen och Miljöbalkens försäkringar (Swedish Government Official Reports), 2007:21, Stockholm: Fritzes.

\section{About the Author}

Erik Lenntorp is doing post-doctoral work at the Department of Management and Engineering, Linköping University, Sweden. His current research is focused on licensing and liability, especially with respect to large accidents in energy production. He holds a Master of Science from Lund University, a European Master in Law and Economics, and a Ph.D. in Economics from Linköping University. The Ph.D. thesis was written on the economic analysis of licensing. 